\title{
Social Impact of a Publication
}

Miguel Abambres

Recognition of the importance of some publication for the well-being of the society. Such recognition is measured, among other factors, by the quantity of people positively affected (directly or indirectly) by the innovation proposed in that publication. Examples of innovations implemented in a society are:

(a) More effective mathematical models in infrastructure design codes.

(b) Prosthesis models that considerably improve the quality of life of their users.

(c) Natural medicine that cures some types of cancer in a few months without dangerous side effects and the need of any other treatment.

(d) Novel financial-economic model allowing each nation to erase extreme poverty.

(e) Clinical integration of a therapy that eliminates the need of drugs for depression treatment.

(f) Replacement of all fossil fuel by the ecofriendly biofuel.

(g) New soil and water treatment techniques allowing the sustainable increase of the life span of several animal and vegetable species.

As in 'Bye Bye Peer-Reviewed Publishing ' [1]

\section{References}

1. ${ }^{\wedge}$ https://www.researchgate.net/publication/332626809 Bye Bye PeerReviewed Publishing 